UCRL-JC-128356

Preprint

\title{
Application of Total Internal Reflection Microscopy for Laser Damage Studies on Fused Silica
}

\author{
Lynn M. Sheehan \\ Mark R. Kozlowski \\ David W. Camp
}

This paper was prepared for submittal to XXIX Annual Symposium on Optical Materials

for High Power Lasers

Boulder, $\mathrm{CO}$

October 6-8, 1997

December 1997

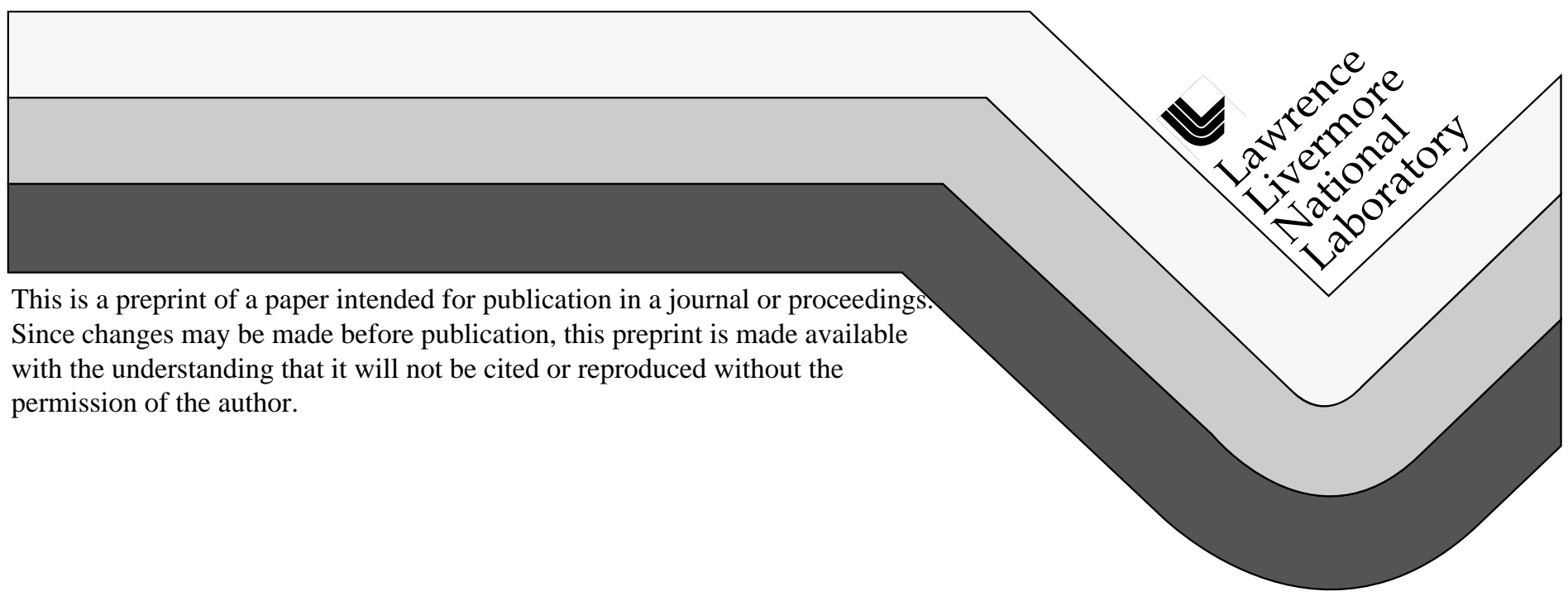




\section{DISCLAIMER}

This document was prepared as an account of work sponsored by an agency of the United States Government. Neither the United States Government nor the University of California nor any of their employees, makes any warranty, express or implied, or assumes any legal liability or responsibility for the accuracy, completeness, or usefulness of any information, apparatus, product, or process disclosed, or represents that its use would not infringe privately owned rights. Reference herein to any specific commercial product, process, or service by trade name, trademark, manufacturer, or otherwise, does not necessarily constitute or imply its endorsement, recommendation, or favoring by the United States Government or the University of California. The views and opinions of authors expressed herein do not necessarily state or reflect those of the United States Government or the University of California, and shall not be used for advertising or product endorsement purposes. 


\title{
Application of Total Internal Reflection Microscopy for Laser Damage Studies on Fused Silica
}

\author{
Lynn M. Sheehan, Mark Kozlowski, David W. Camp \\ University of California \\ Lawrence Livermore National Laboratory \\ P. 0. Box 808, L-496 \\ Livermore, CA 94550
}

\begin{abstract}
Damage studies show that the majority of damage on ultraviolet grade fused silica initiates at the front or rear surface. The grinding and polishing processes used to produce the optical surfaces of transparent optics play a key role in the development of defects which can ultimately initiate damage. These defects can be on or breaking through the surface or can be sub-surface damage. Total Internal Reflection Microscopy has been documented as a tool for revealing both sub-surface and surface defects in transparent materials. Images taken which compare both Total Internal Reflection Microscopy and Atomic Force Microscopy show that the observed defects can be less than one micron in size. Total Internal Reflection Microscopy has the added benefit of being able to observe large areas (1 square millimeter) with sub-micron detection. Both off-line and in-situ systems have been applied in the Lawrence Livermore National Laboratory's damage laboratory in order to understand defects in the surface and subsurface of polished fused silica. There is a preliminary indication that TIRM quality can be related to the damage resistance. The in-situ microscope is coupled into a $355 \mathrm{~nm}, 7.5 \mathrm{~ns}, 10 \mathrm{~Hz}$ $\mathrm{Nd}$ :YAG laser system in order to study damage occurring at localized scatter sites revealed with the Total Internal Reflection Microscopy method. The tests indicate damage initiating at observed artifacts which have many different morphologies and damage behaviors. Some of the scatter sites and damage morphologies revealed have been related back to the finishing process.
\end{abstract}

Key words: Total Internal Reflection Microscopy, Atomic Force Microscopy, Fused Silica, Localized Scatter, Laser Induced Damage

\section{Introduction}

Lawrence Livermore National Laboratory (LLNL) is searching for tools to investigate damage related phenomenon on polished fused silica surfaces. The damage initiation of interest is at high intensity 355 nanometer $(\mathrm{nm})$ laser light. This work is in support of the National Ignition Facility which will include 192 separate laser beam lines operating at high peak power. The final focusing and beam conditioning optics are made using polished fused silica. Damage to these optics can occur for many reasons, but the majority of damage is initiated on the finished surfaces of the optic at discrete points. In order to understand laser induced damage on fused silica surfaces a previously documented tool called the Total Internal Reflection Microscope (TIRM) was applied ${ }^{(1-5)}$. This instrument shows promise for investigating defects on the surface, as well as the sub-surface of a finished optic.

There are three experiments presented in this paper. The first is the relation of TIRM to Atomic Force Microscopy (AFM). The AFM allows the surface topography to be measured to the nanometer level. Combining AFM and TIRM allowed us to investigate what defects where causing the scattered light observed with TIRM. Since AFM is only sensitive to surface topography, the experiment also tells us if the TIRM defect is surface or sub-surface. The second experiment used TIRM as a measure of quality of an optic and compared this to the optics damage resistance. This would be useful as a quality control tool for fused silica surfaces. The last experiment coupled the TIRM in-situ to a laser damage test facility at $355 \mathrm{~nm}$ in order to observe damage initiation and growth. 


\section{Total Internal Reflection Microscope Arrangements}

This technique relies on the optical parameter of total internal reflection. This happens when going from a high index to a low index material at an angle which is greater than the critical angle of the material. For fused silica with an index of 1.463 at $488 \mathrm{~nm}$ the critical angle is 43.1 degrees. The experiments where done with a 2 watt argon ion laser operating at $488 \mathrm{~nm}$. The operating power used for each experiment may be different as noted. A generic diagram for a TIRM is shown in Fig. 1. This arrangement was used for off-line testing of optics in order to determine the optics relative quality in TIRM. A photograph of the LLNL microscope is shown in Fig. 2. This arrangement has the least amount of optical noise and provided the best control for measuring parts over time and getting similar results. The angle of TIR is 45 degrees for this arrangement. A half-waveplate is used to control the laser beam polarization which can effect the TIRM image.

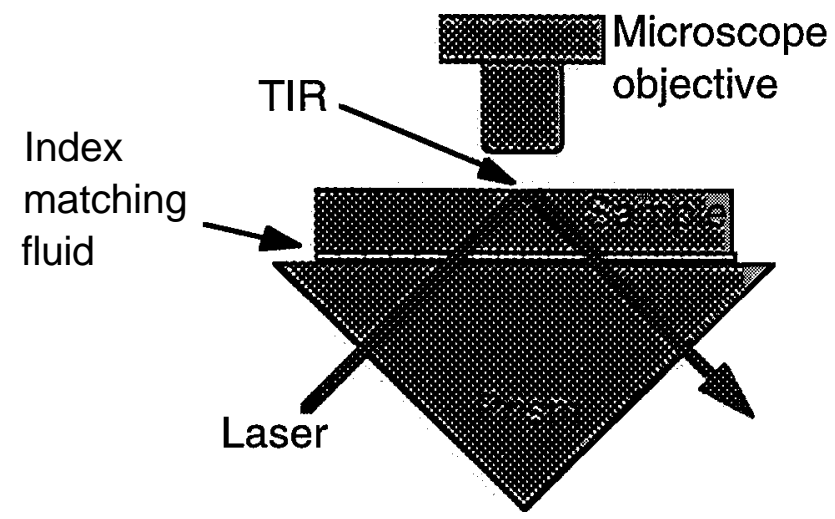

Fig. 1 TIRM microscope setup for qualitative comparison of optics

The next TIRM arrangement shown in Fig. 3 was used to conduct TIRM in-situ to a AFM. In this arrangement the beam is introduced to the sample through the side of the sample instead of using a prism and index matching fluid. The angles used for this experiment are shown in Fig. 4.

The last arrangement presented is for the in-situ damage experiment. In this case a prism is again used to introduce the beam to the sample. Depending on the size of your probe beam and the size of the prism, an area on the sample can be investigated. These parameters are shown in Fig. 5. The rear surface was investigated since this is where the majority of damage occurs.

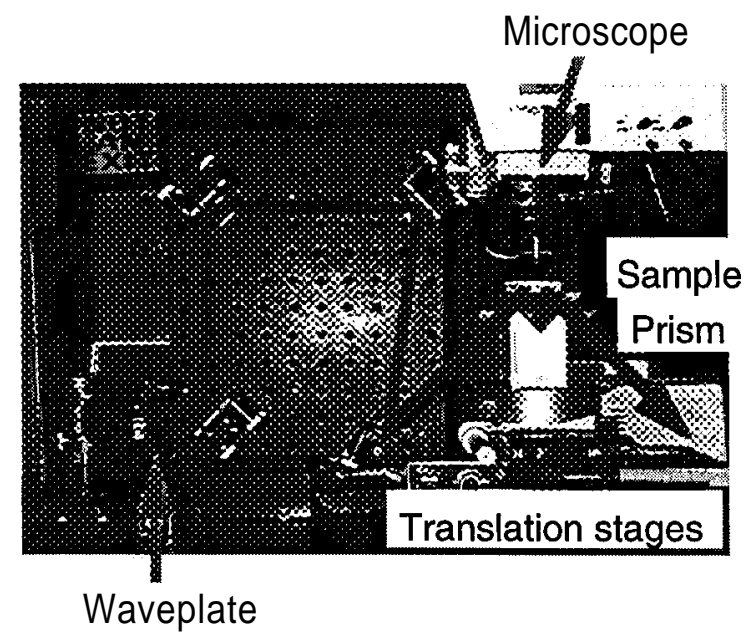

Fig. 2 TIRM arrangement for quantification of TIRM images 


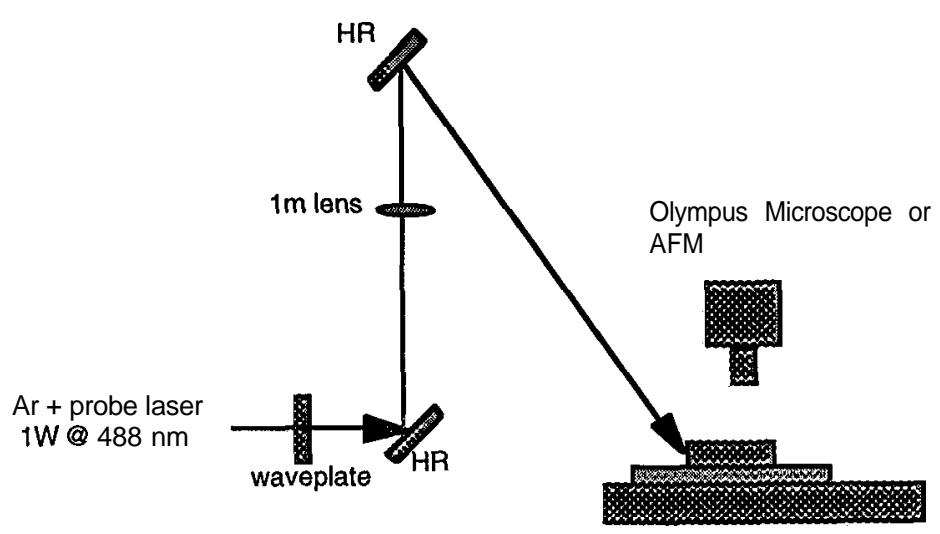

Fig. 3TIRM arrangement for use in-situ to AFM

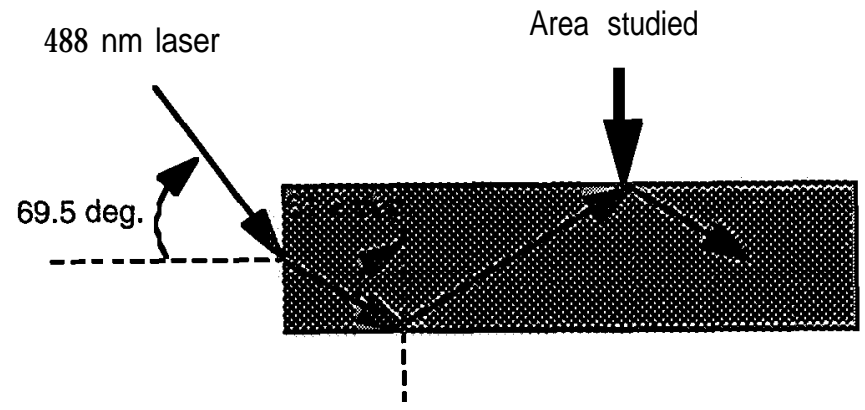

Fig. 4 TIRM arrangement when the laser is introduced through the side of the sample and investigated on its second TIR.

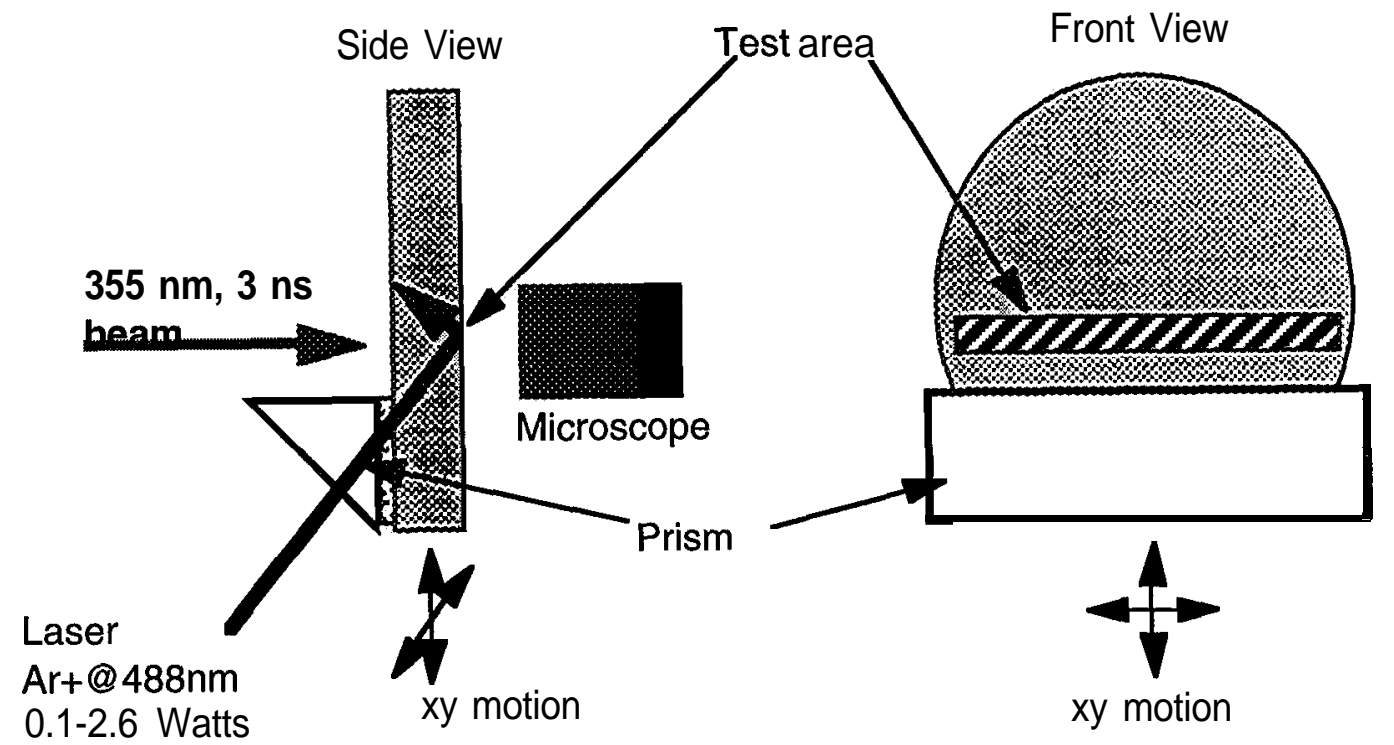

Fig. 5 TIRM in-situ to damage test system. 


\section{Quantitative TIRM as a Measure of Damage Resistance}

One issue with using TIRM alone as a diagnostic for damage resistance is that the images contain all of the TIRM visible defects. Some percentage of these will be defects which initiate damage and some will not (see section 5). Along these lines an optic may have a quantitatively poor TIRM, but the defects may be damage resistant. On the contrary the optic may have few defects, but they are very susceptible to damage. Current observations presented here show that in some cases a good correlation can be made between TIRM quality and damage threshold. This may not be true in all cases due to the above uncertainty. As shown here TIRM is not able to non-destructively identify those defects which will cause damage.

Using the arrangement shown in Fig. 1, several different optics where investigated which had varying amounts of sub-surface and surface damage left from the finishing process as well as varying damage thresholds. Four TIRM images are shown in Fig. 6, all are taken with a argon ion power of 1 watt. The average R:1 mapping damage threshold and the defects statistics for the parts are shown in Table 1.

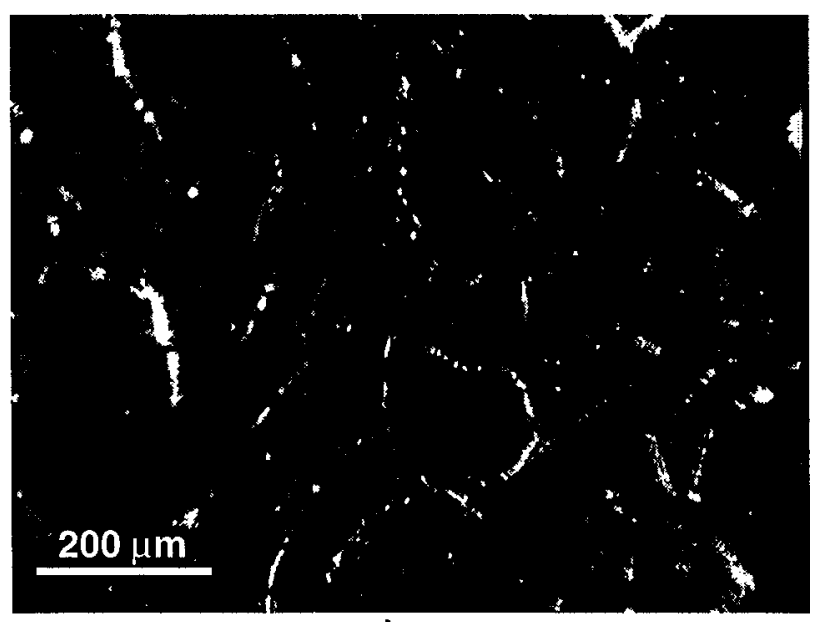

a)

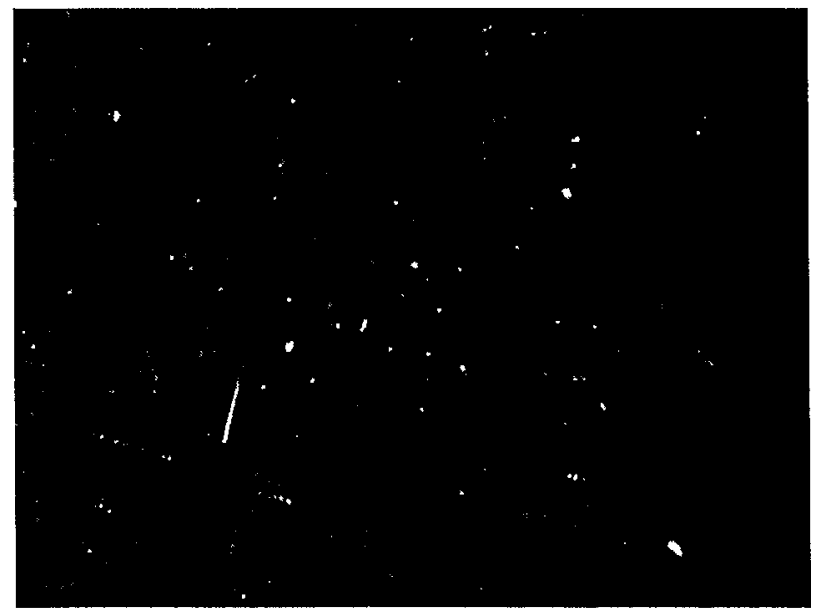

c)

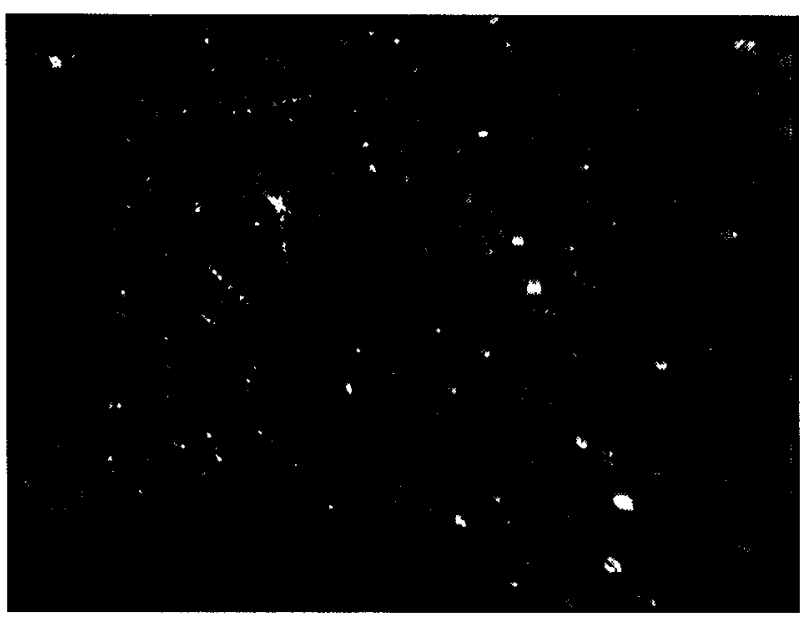

b)

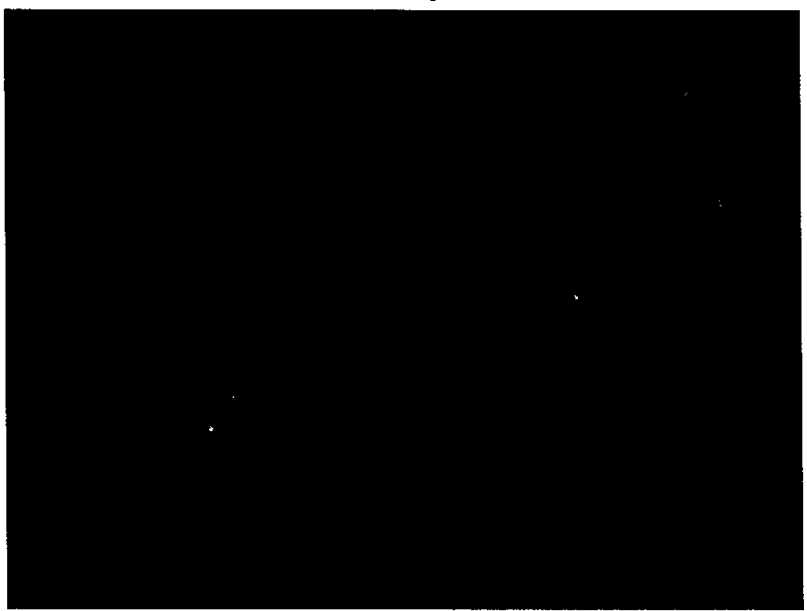

d)

Fig. 6 a-d Four TIRM images from fused silica surfaces prepared with different process steps, each having a different average damage threshold. The optics are labeled as they are here, a) Optic A, b) Optic B, c) Optic C, d) ‘Optic D. 
Table 1 Quantitative comparison of TIRM images in Fig. 6

\begin{tabular}{|c|c|c|c|c|}
\hline Parameter & Optic A & Optic B & Optic C & Optic D \\
\hline $\begin{array}{r}\text { R:1 avelDarge } 8355 \text { nm, ns } \\
\left(\mathrm{J} / \mathrm{cm}^{2}\right)\end{array}$ & 4.2 & 13.7 & 19.1 & 24.2 \\
\hline Defects pequareillimeter & 4493 & 6058 & 4064 & 38 \\
\hline $\begin{array}{c}\text { Percent area obscured by defects } \\
(\%)\end{array}$ & 4.6 & 2.4 & 1.6 & 0.02 \\
\hline
\end{tabular}

These optics where chosen in order to show a broad range of both TIRM defects and damage performance. All of the images are from investigations on two inch diameter parts fabricated for LLNL. For use as a quality control tool, TIRM needs to be quantified and related to the damage performance. This is achieved in two ways for this set of parts. The first is to measure the quantity of defects per square millimeter of area in a TIRM image. The second quantification is to determine how much of the total area of a TIRM image is taken up by TIRM defects. Image processing software is used to determine these values. Since TIRM as applied here is an average quantification of the optic, the average R:I mapping value was used for the damage threshold. R:1 mapping was introduced in a past symposium ${ }^{(6)}$ as a way to measure the statistical behavior of a damage specimen.

The results of the comparisons are plotted in Fig. 7 and 8 . The quantity of defects per square millimeter is a indication of possible damage initiators, but it can be deceiving as in the case of Optic A. Optic A does not have a large amount of defects, but the ones that exist are large in size. To take this into account we plot damage performance against percentage of area obscured by defects as shown in Fig. 8. For this set of 4 parts, the obscured area measure seems to give the best relationship to damage.

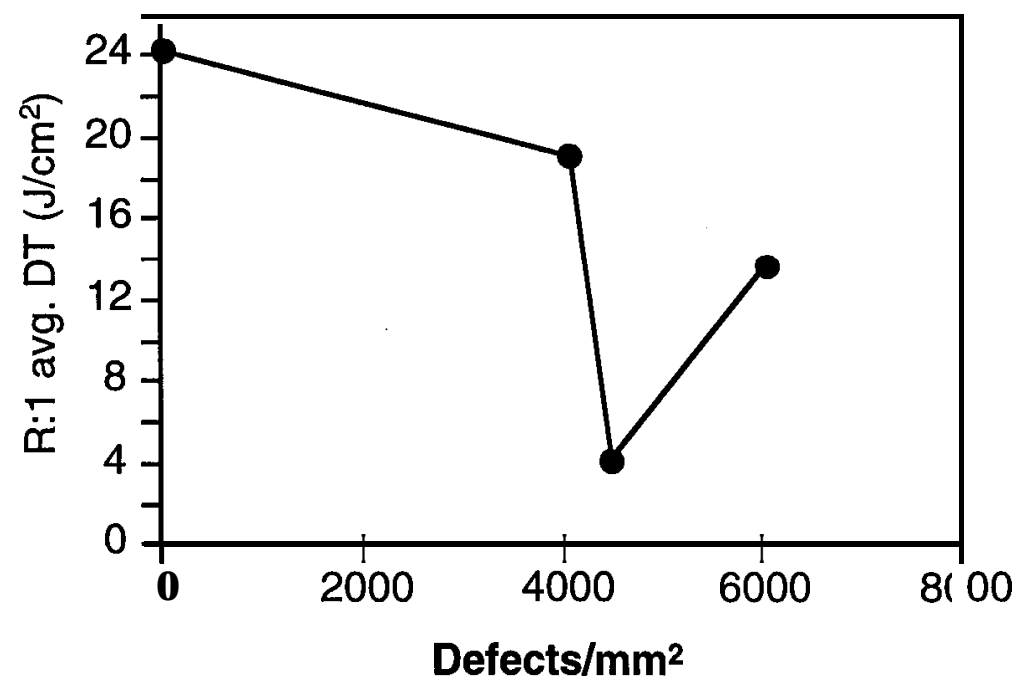

Fig. 7 Dependence of damage threshold on quantify of TIRM defects per square millimeter of area 


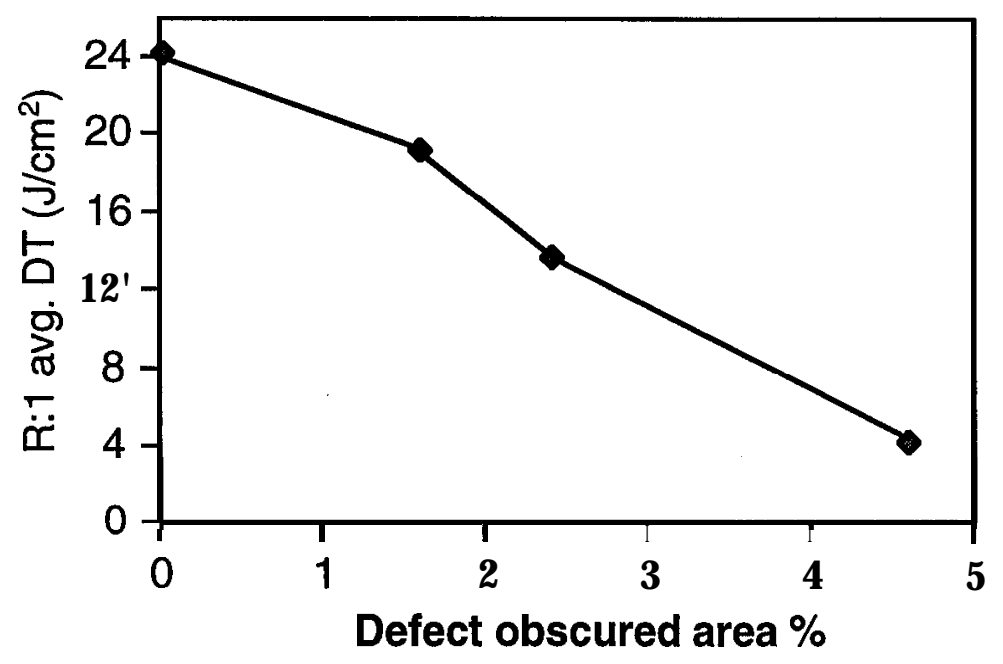

Fig. 8Dependence of damage threshold on percent area obscured by TIRM defects

\section{TIRM in-situ to AFM}

The arrangement shown in Fig. 3 and Fig. 4 was used to investigate the origin of the TIRM defects. The AFM was used to identify surface topography to a better than $100 \mathrm{~nm}$ spatial resolution and $1 \mathrm{~mm}$ vertical. This topography was then related to a TIRM image. One of the problems which arose during this experiment is the scale length difference in the images collected between the two instruments (-10 times). In Fig. 9 a) the area within the TIRM image which could be investigated using AFM is shown as a white box. That area is cropped out of the full size TIRM image and compared to the AFM acquired image as shown in the two bottom photos Fig. $9 \mathrm{~b}$ and c. The sizes of the comparable defects area shown in Table 2. The sensitivity of the TIRM method is revealed to be sub-micron, with the smallest lateral defect seen at this site being $240 \mathrm{~nm}$ in width. The lowest defect depth relative to the surface was 3.4 $\mathrm{nm}$. It is obvious that TIRM can be used to detect very small surface features. Although several of the defects could be correlated between the two images, Fig. 9 b, c, defects labeled a-d, there are many defects in the images that do not correlate. This goes in both directions, AFM defects that do not appear in TIRM and TIRM defects not visible in AFM. It should be noted that the resolution of the AFM for this image is approximately $100 \mathrm{~nm}$ per pixel. Because of this it can only be said that some TIRM defects which are not visible in the AFM image are either sub-surface, or are smaller than the detection limit of the AFM. 


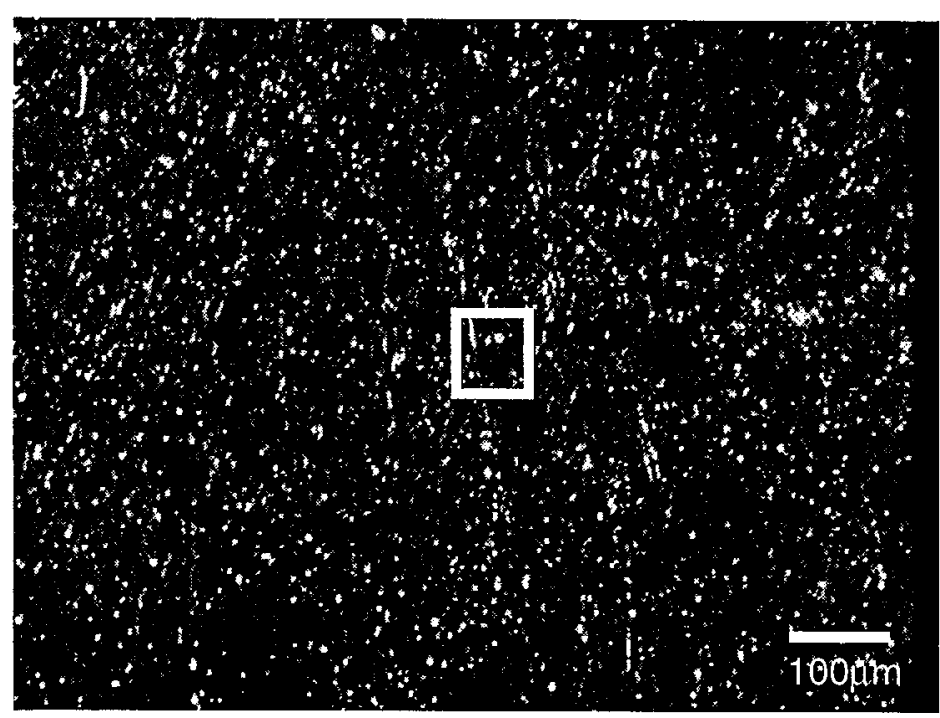

a)

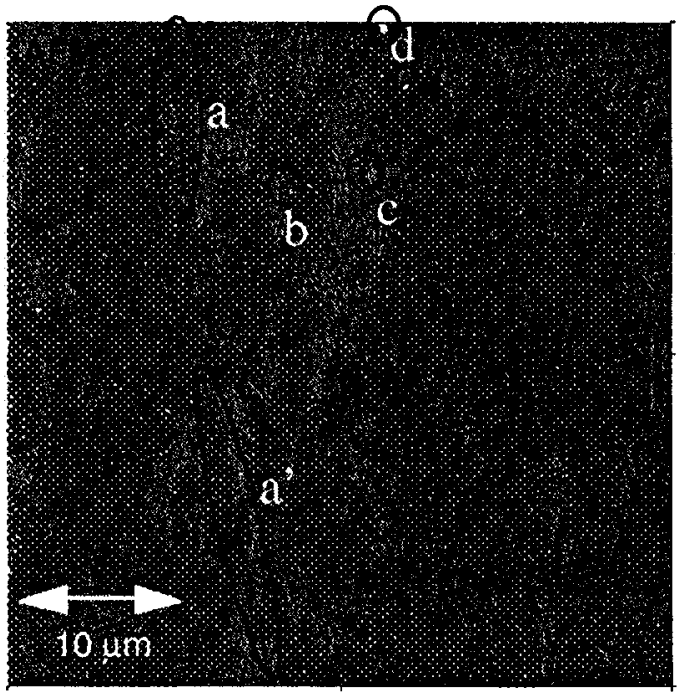

b)

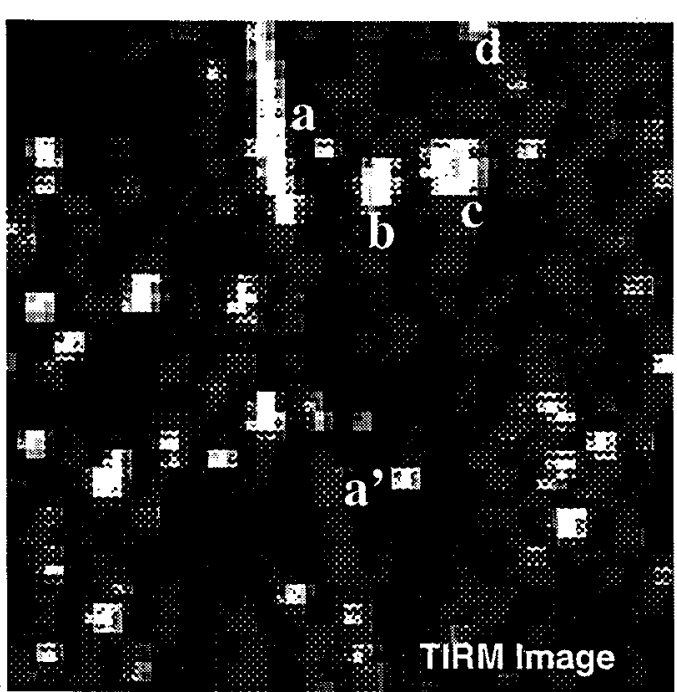

c)

Fig. 9 a) AFM scan area within a TIRM image. The AFM image b) is compared on scale to the TIRM image c) which is cut form the original a). Comparison of defects can then be made.

A second site is shown in Fig. 10. Here just the AFM and cropped TIRM image are shown. The scratch which is visible is $346 \mathrm{~nm}$ wide and $2.8 \mathrm{~nm}$ deep. The second bright defect to the left of the scratch in the TIRM image is not visible in the AFM. The third site (Fig. 11) shows a set of pinholes in the surface that where detected by both TIRM and AFM. A gain, all of the defects measured where less than $400 \mathrm{~mm}$ in width and less than $100 \mathrm{~nm}$ in depth (Table 3).

Table 2 Defect dimensions for those identified in Fig. $9 \mathrm{~b}$ and c.

\begin{tabular}{|l|l|l|l|}
\hline Defect & description & width $(\mathrm{nm})$ & depth or height $(\mathrm{nm})$ \\
\hline a & scratch & 294 & 6.3 \\
\hline a' & scratch & 240 & 3.4 \\
\hline b & pit & 325 & 5 \\
\hline c & pit & 650 & 25 \\
\hline d & bump & 650 & 64 \\
\hline
\end{tabular}




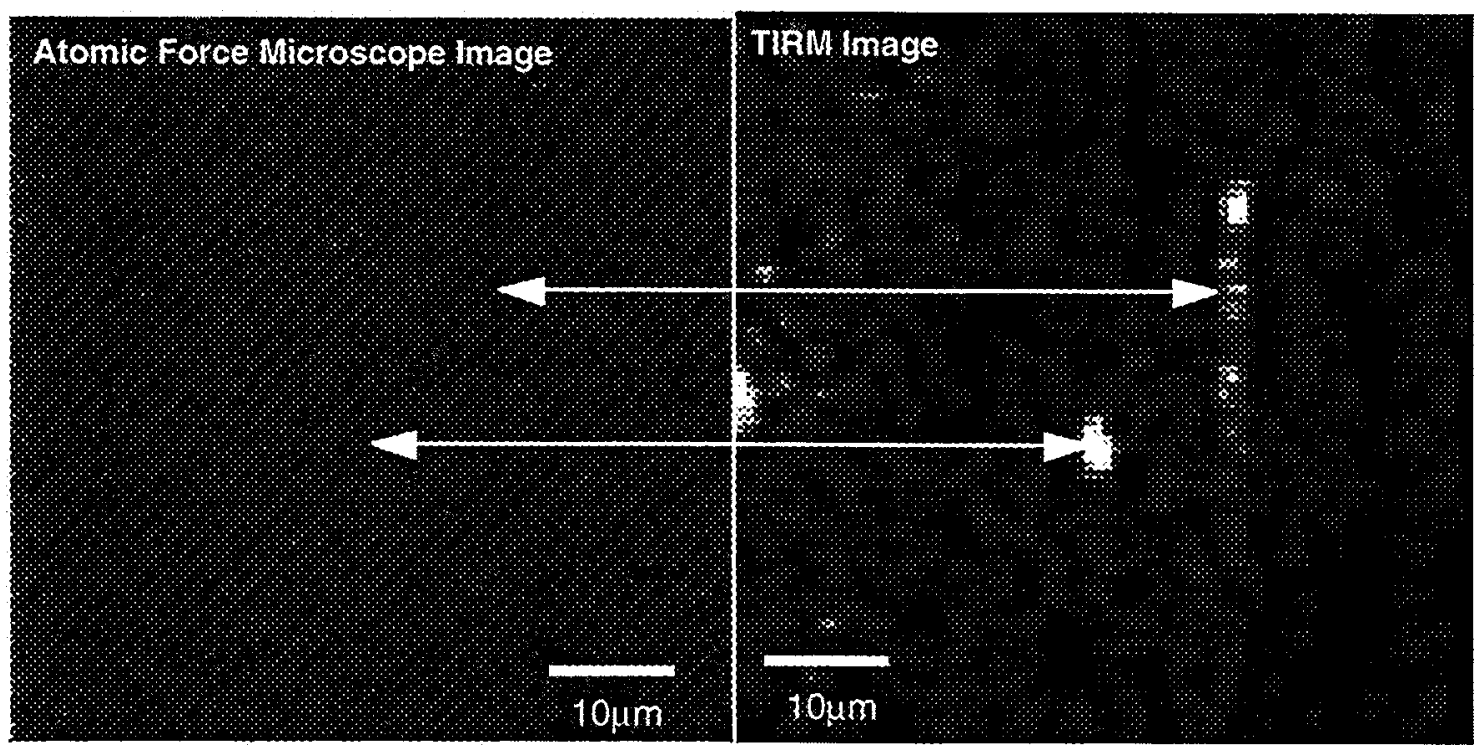

Fig. 10 Scratch is visible in both AFM and TIRM. The bright spot on the TIRM is not visible in the AFM.
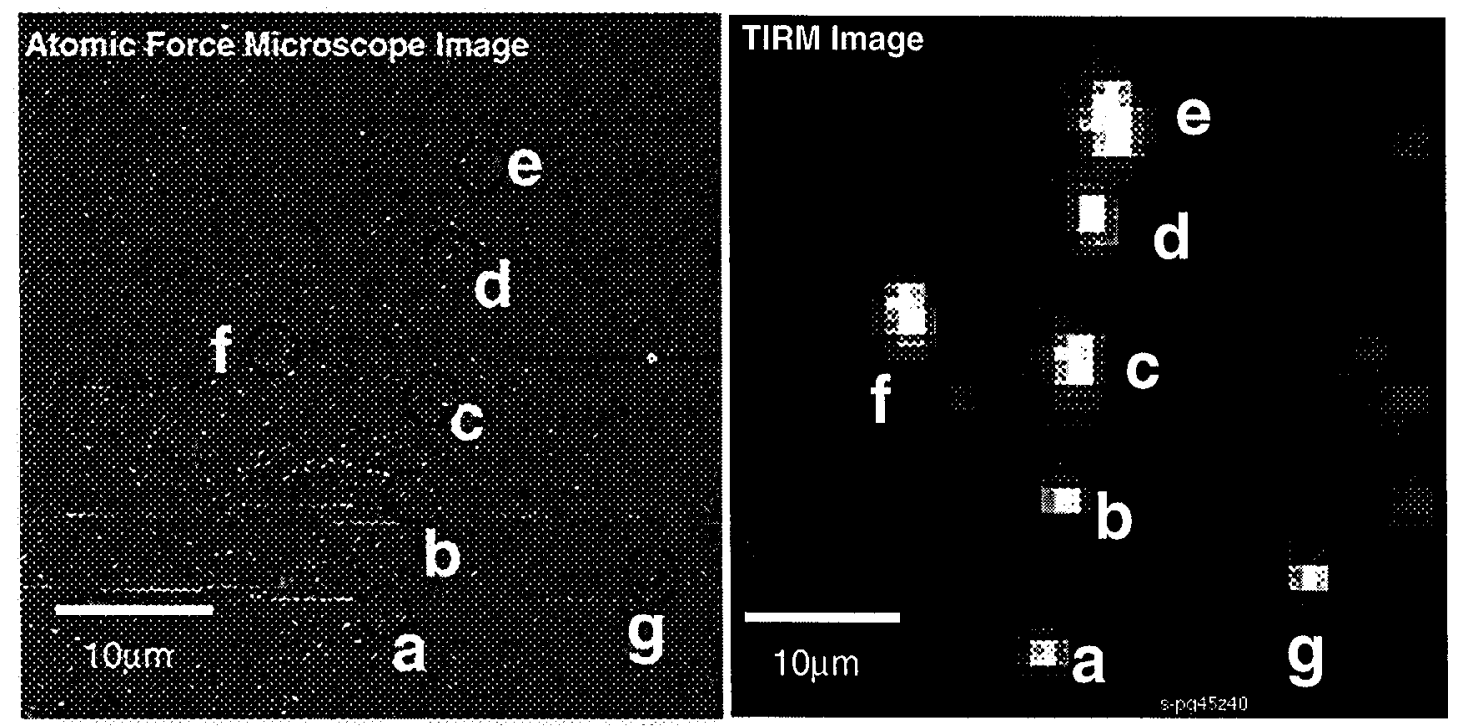

Fig. 11 AFM and TIRM images showing the detection in both of small pits characterized in Table 3.

Table 3 Defects measured from AFM images in Fig. 11.

\begin{tabular}{|l|l|l|l|}
\hline Defect & description & width $(\mathrm{nm})$ & depth or height $(\mathrm{nm})$ \\
\hline a & pit & 389 & 11 \\
\hline b & " & 389 & 10 \\
\hline c & a & 284 & 27 \\
\hline d & a & 316 & 24 \\
\hline f & a & 379 & 92 \\
\hline g & a & 284 & 37 \\
\hline
\end{tabular}




\section{TIRM in-situ Laser Damage System}

The arrangement for this experiment was discussed in section 2 Fig. 5 . The probe beam is introduced through a prism coupled to the front surface of the optic. The damage laser beam and the back surface TIR beam are co-aligned and the site is observed with a microscope. Until TIRM was implemented the LLNL standard diagnostic for fused silica damage investigation was Nomarski and Darkfield microscopy. The advantage of TIRM is the amount of defects revealed as compared to the darkfield method (Fig. 12). The problem arises as discussed earlier that there may be too many defects revealed, many of which may not be a damage problem.
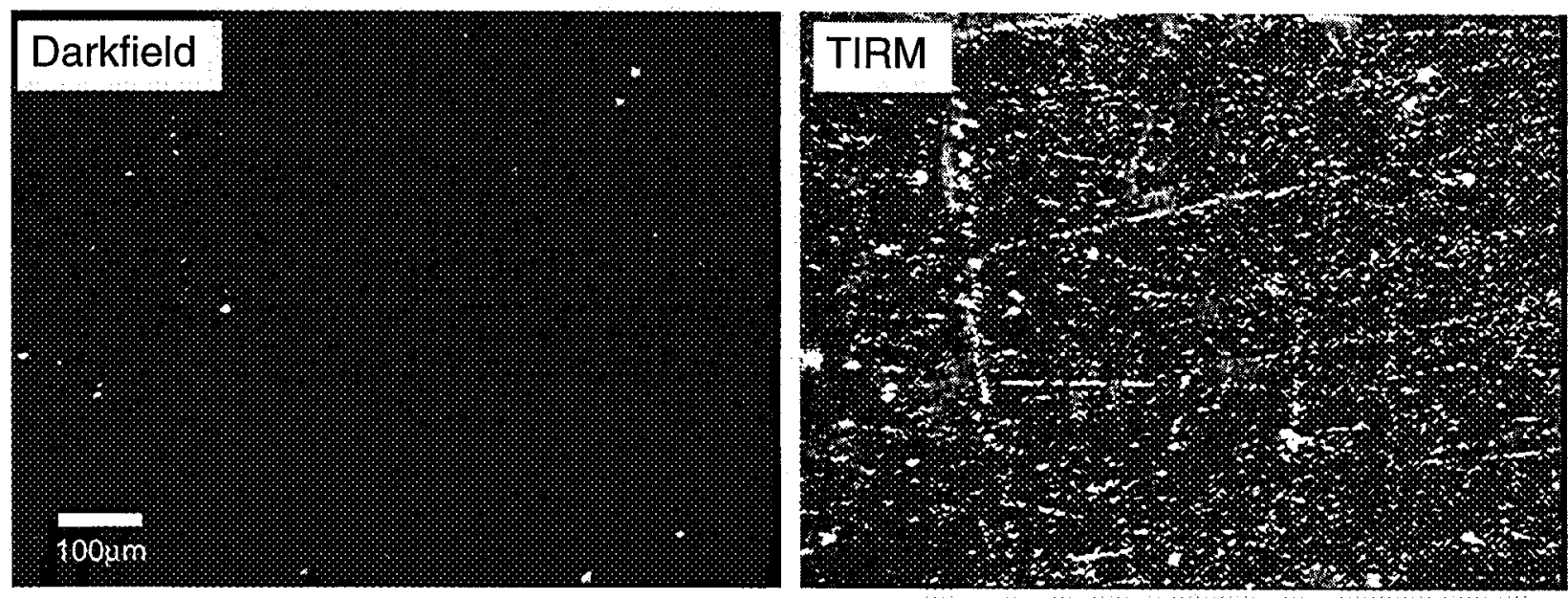

Fig. 12 Compared to darkfield microscopy, TIRM reveals far more information about the fused silica surface at any particular site.

The images for this test where captured with a framegrabber in a computer so that they could be postprocessed. In Fig. 13 a series of pictures taken are shown. The first two pictures a and b are the before and after damage TIRM images. Because there are so many defects, a image processing program was used to subtract image a from image $b$ in order to highlight only the defects which damaged and any new sites that may have formed. This technique worked well to identify whether or not a defect had a visible precursor. If a precursor existed in image a, the subtracted image showed a dark spot in the center of the damage spot (Fig. 14). Some sites where identified that did not show a visible precursor. This could be due to either damage initiation at a non-visible defect, or debris which was generated during damage which is still within the field of view of the microscope. The later is most likely the source because other investigations using AFM and Scanning Electron Microscopy (SEM) show that a significant amount of debris is generated even from pinpoint damage.

The other noticeable conclusion is that not all of the existing defects caused damage. This is not surprising, but it does make it difficult to determine whether or not an optic is damage resistant as discussed in section 3. Future efforts will include the coupling of TIRM to other damage diagnostics to try to identity defects which have a higher probability of damage. During this experiment damage was found to initiate at all kinds of defect morphologies. In Fig. 15 some of these damage morphologies are displayed in the difference image form; a) damage at pinpoints, b) damage in discrete points along a line, c) damage at large pinpoints, d) damage at large visible scratches. Again the dark centers of the defects in the difference image represent the preexisting defect. 


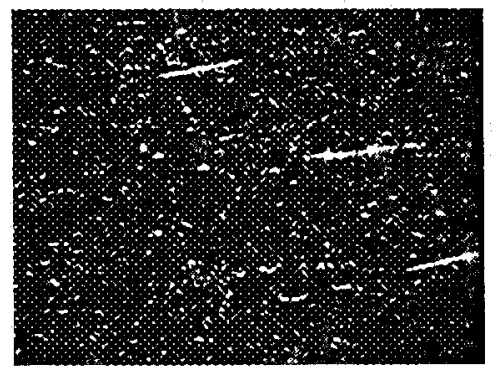

a)

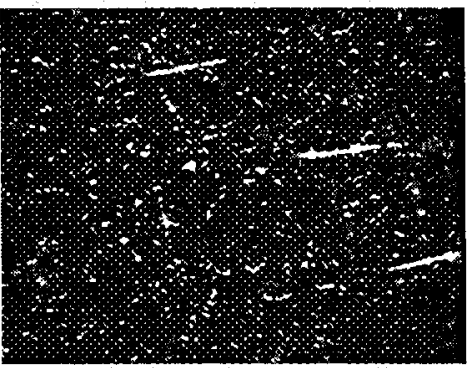

b)

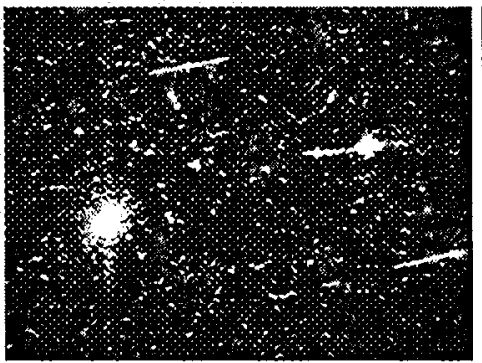

d)

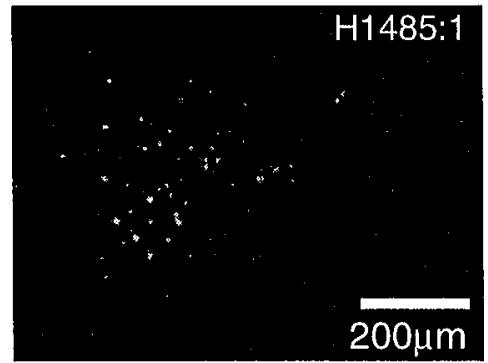

c)

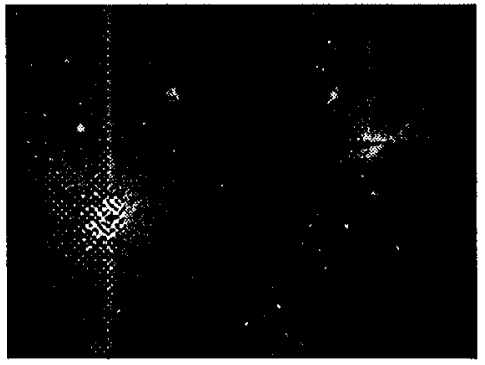

e)

Fig. 13 TIRM images acquired during in-situ experiment include a) before image, b) image after one laser pulse, c) result of subtracting image a from image $b, d$ ) is damage which occurred after $\mathrm{N}$ more shots (stopped upon catastrophic damage), e) is the subtraction of image b from image $d$ which reveals damage which occurred after shot one up to shot $\mathrm{N}$.

Although most of the damage observed initiated at identifiable localized defects, one damage morphology was made up of thousands of pinpoints which had no visible precursor (Fig. 16). These thousands of small damage sites where on the order of 1 micron wide and when they reached high concentration, the damage became visible by eye and looked like a grey colored spot. This damage morphology was uniform across the parts as shown in Fig. 17 which is a TIRM image in an area which has been raster scanned. A cluster of pinpoints is initiated at each site as the part is scanned though the laser beam. In this case the area which was scanned was visible to the eye and the term "grey haze" was adopted to describe this visible onset of this damage morphology.

Using an AFM the damage was identified to be sub-micron diameter pits and debris. The pits where less than a few hundred nanometers deep. An example of one of the defects is shown in Fig. 18 which is a AFM lineout through the defect. The shallow depth and uniformity of the damage led to the belief that the damage is related to some absorbing contaminant which was incorporated into the polishing layer of the finished surface. This layer is well documented in the optical finishing field ${ }^{(7)}$. Working off of this theory a second sample was tested which had $100 \mathrm{~nm}$ of material removed using a Hydrofluoric acid etch process. The effect of this etch was clearly evident as shown in Fig. 19. Image a and $b$ are the before image and the difference image showing damage generated at $11.2 \mathrm{~J} / \mathrm{cm}^{2}$ on a part as received. The bottom images $c$ and $d$ are before and difference images on a part after etching $100 \mathrm{~nm}$ of material off and irradiating it at $13.3 \mathrm{~J} / \mathrm{cm}^{2}$. After the etch treatment there are much fewer pinpoints, although the surface before (image c) looks worse than the first part (image a). 


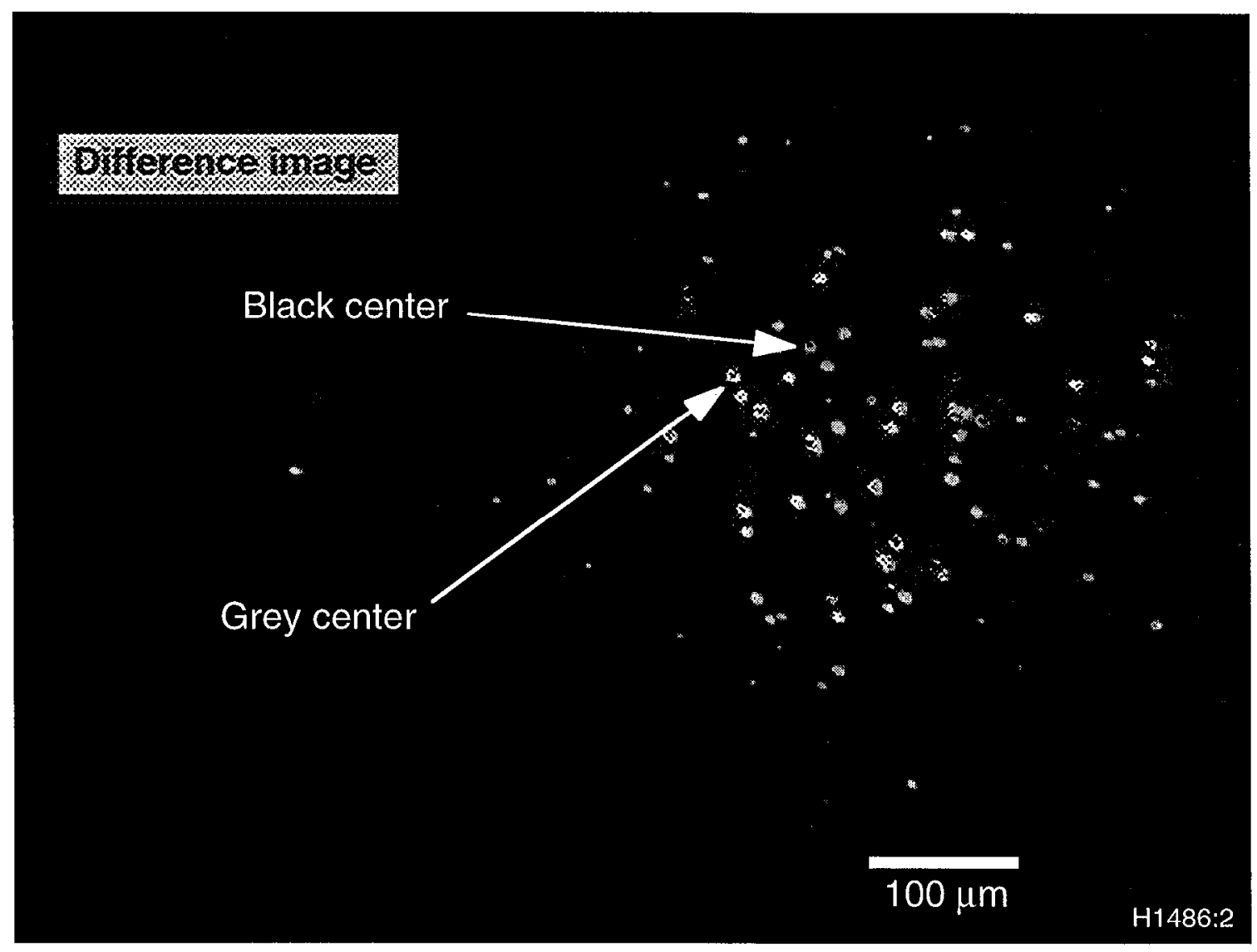

Fig. 14 The result of subtracting the before TIRM image from the after damage TIRM image allows the identification of dark centers which indicate that there was a precursor to the damage.
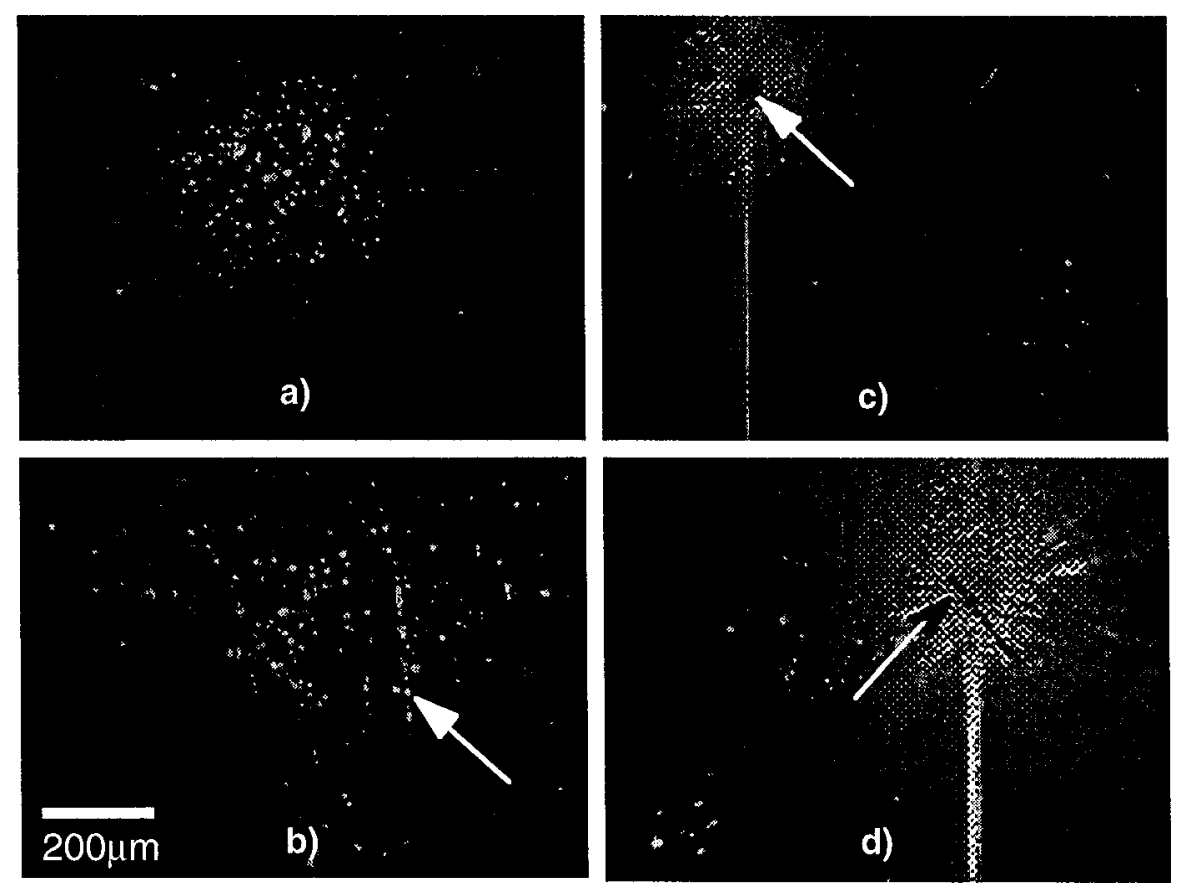

Fig. 15 Damage initiated at a variety of defects a) small pinpoints, b) lines of pinpoints, c) large pinpoints, d) visible scratches. 


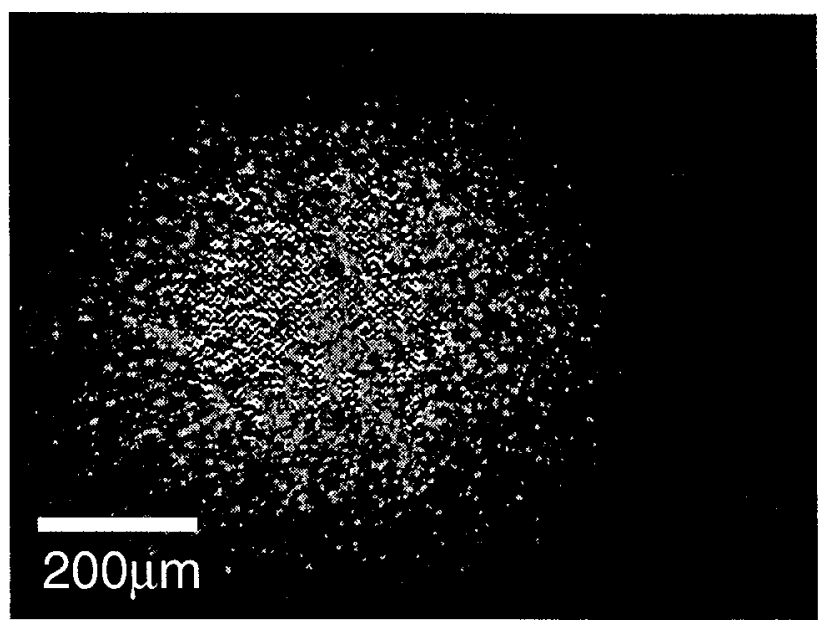

Fig. $16 \mathrm{High}$ density of pinpoints generated on some samples is referred to as grey haze.

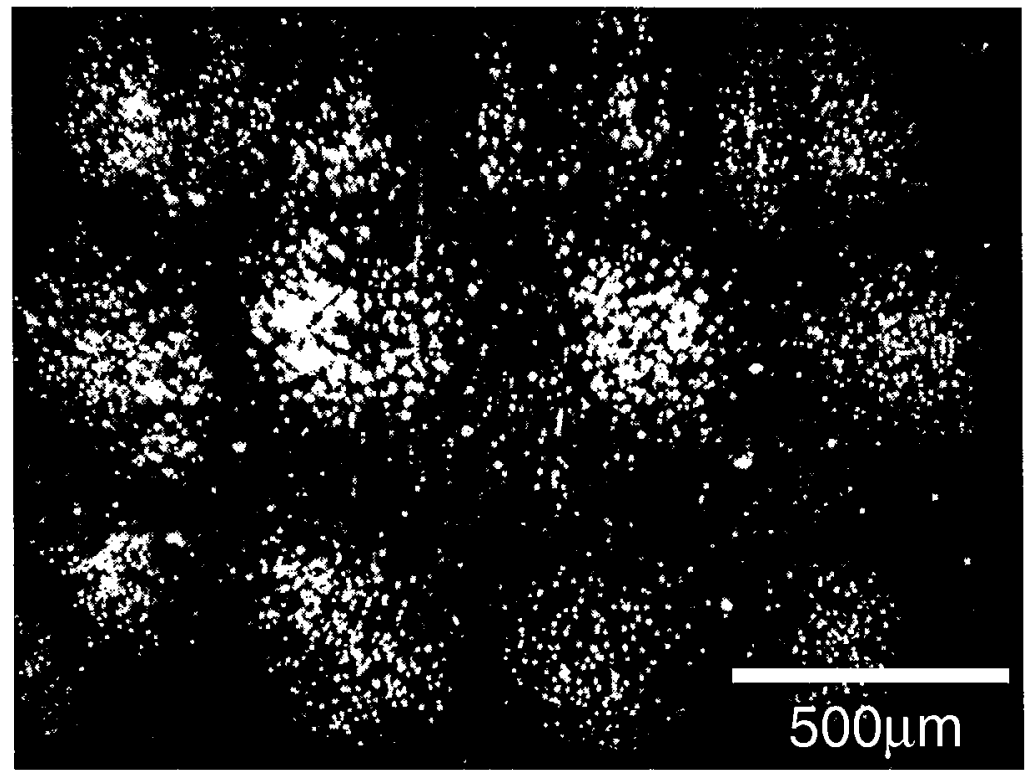

Fig. 17 Grey haze damage morphology is uniform across a part as shown in this area which had been raster scanned. Each cluster represents a site hit by the laser beam during the scan.

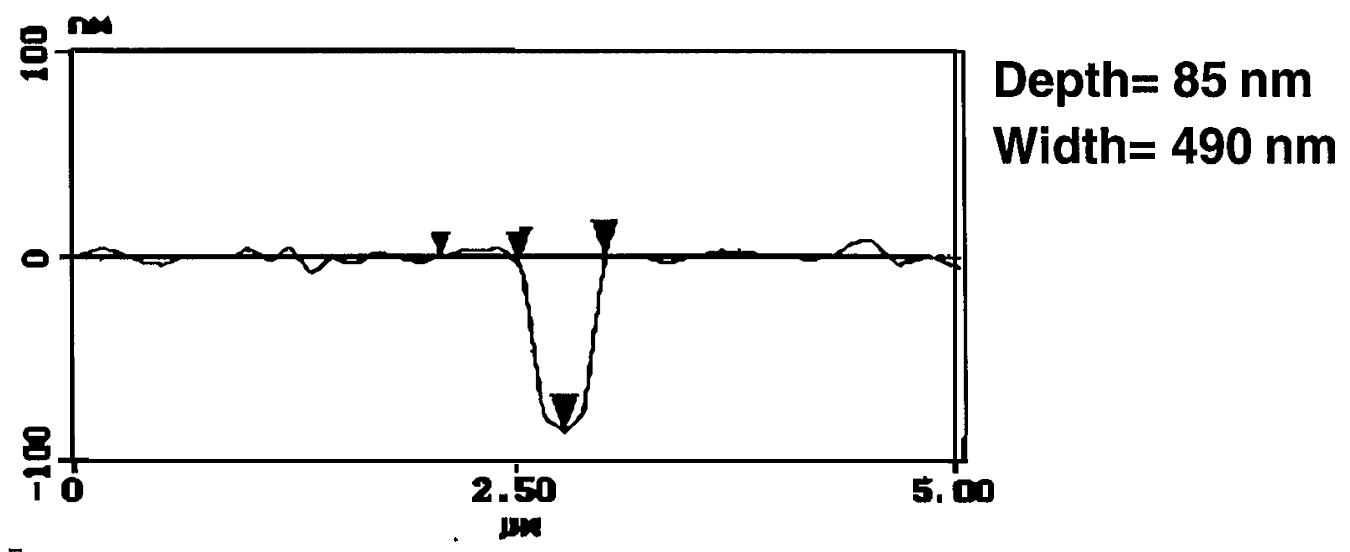

Fig. 18 AFM line out of pit created in the area of the grey haze damage morphology. 


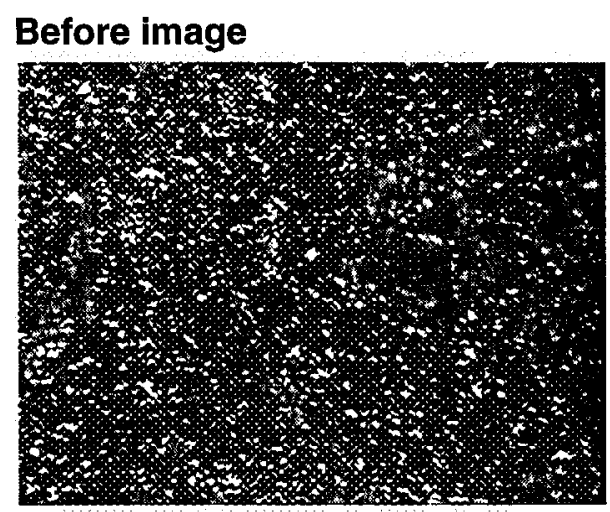

a)

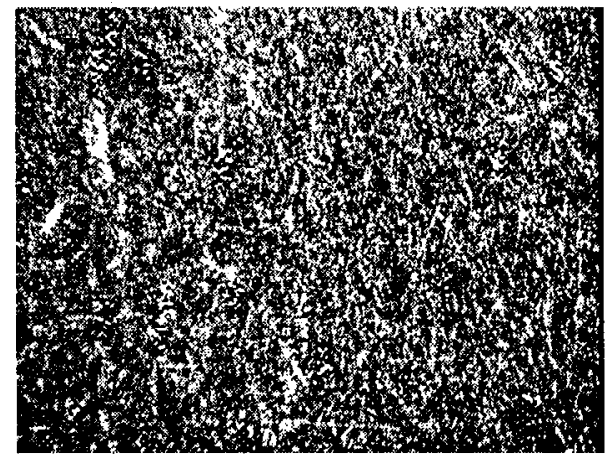

c)

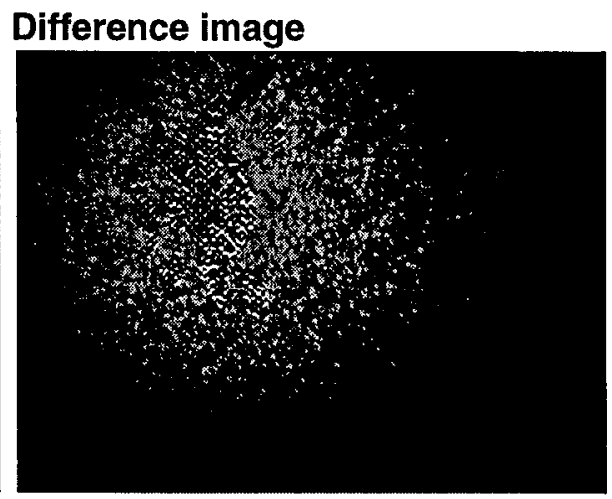

b)

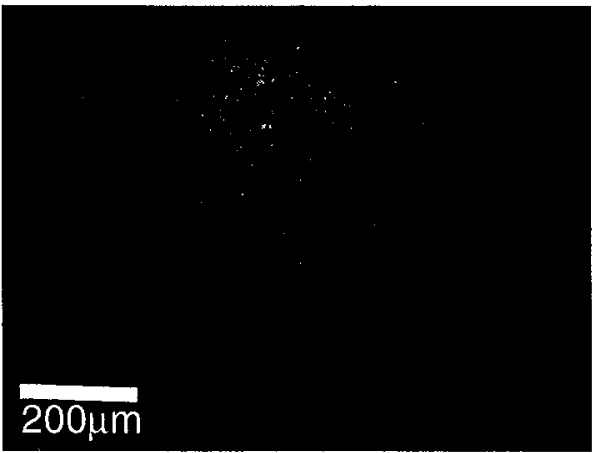

d)

Fig. 19 Images a) and b) are the before image and the difference image of a part as received which demonstrated the grey haze damage morphology. Images c) and d) are from a similar part after etching $100 \mathrm{~nm}$ off of the surfaces.

\section{Conclusions}

Total Internal Reflection Microscopy has been applied to the study of fused silica polished surface using several different arrangements. This microscopy was able to identify sub-micron defects over a large viewing area $\left(1 \mathrm{~mm}^{2}\right)$. When compared to A tomic Force Microscopy images, TIRM artifacts where detected to sizes less than $300 \mathrm{~nm}$ in lateral width and less than $10 \mathrm{ntn}$ in vertical dimensions. The instrument is simple to apply and highly sensitive.

Use of TIRM as a quality control tool for prediction of damage performance shows some promise. When analyzing the images both the quantity of defects and the total area they obscure should be considered. With the current knowledge, this application will be difficult due to the fact that not all TIRM defects initiate damage. Coupling of TIRM to a secondary diagnostic which is capable of identifying a damage parameter such as localized heating, may allow one to eliminate non-damaging defects from the images.

Coupling TIRM in-situ to a damage test station provided insight into the initiation and growth of damage on fused silica surface. Compared to darkfield microscopy, TIRM can reveal thousands more defects at the same site. This has distinct advantages for damage measurements and for studying the precursors to the damage. Using this process it was found that one of the damage morphologies referred to as grey haze could be significantly reduced by etching away the surface layer of the optic. 


\section{Acknowledgments}

I would like to thank the following people for all of their help on TIRM image acquisition, AFM image acquisition, and optimization of the experiment procedures: Stan Oberhelmen, Wigbert Siekhaus, Ming Yan, and Ian Thomas of LLNL --- Yann Pierre from CEL-V laboratory in France.

Work performed under the auspices of the U. S. Department of Energy by Lawrence Livermore National Laboratory under Contract No. W-7405-ENG-48

\section{References}

1) Temple, P. A., "Examination of Laser Damage Sites of Transparent Surfaces and Films Using Total Internal Reflection Microscopy", Natl. Bu. Stand. (U.S.) Spec. Publ. 568, pp. 333-341, 1980.

2) Temple, P. A., "Total Internal Reflection Microscopy: a Surface Inspection Technique", Applied Optics, Vol. 20, No. 15, 1981.

3) Jabr, S. N., "Total Internal Reflection Microscopy: Inspection of Surfaces of High Bulk Scatter Materials", Applied Optics, Vol. 24, pp. 1689-1692, 1985.

4) Kranenberg, C. F., Jungling, K. C., "Subsurface Damage Identification in Optically Transparent materials Using a Nondestructive Method", Applied Optics, Vol. 33, No. 19, pp. 4248-4253, 1994.

5) Liao, Z., Cohen, S., Taylor, J., "Total Internal Reflection Microscopy (TIRM) as a Nondestructive Subsurface Damage Assessment Tool", Laser Induced Damage in Optical Materials: 1994, SPIE Vol. 2428, pp. 43-53, 1995.

6) Hue, J., Garrec, P., Dijon, J., "R-on-I Automatic Mapping: A new Tool for Laser Damage Testing”, Laser Induced Damage in Optical Materials: 1995, SPIE Vol. 2714, pp. 90-101, 1996.

7) Hed, P., Edwards, D., Davis, J. "Subsurface Damage in Optical Materials: Origin, Measurement, and Removal", Proc. Subsurface Damage in Glass, ASPE A pril, 1989. 


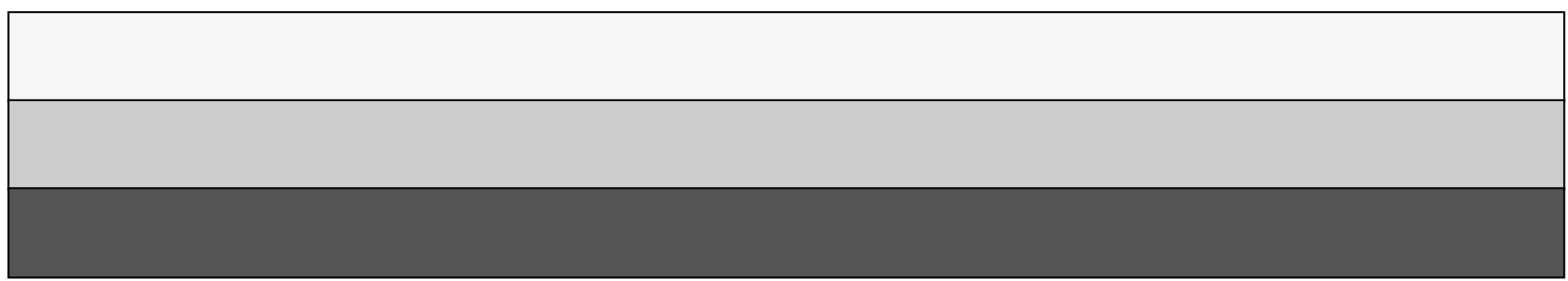

